\title{
A participação das famílias como uma política educativa
}

Family participation as an educational policy

Simone Santos de Albuquerque*

Universidade Federal do Rio Grande do Sul

Resumo $\mathrm{O}$ artigo apresenta parte da pesquisa intitulada Das lógicas familiares às lógicas escolares: caminhos e perspectivas na educação das crianças. O estudo, com uma abordagem qualitativa de cunho etnográfico, partiu do princípio de que o pesquisador deve estar inserido no campo social da investigação. Nesta perspectiva, procurou estabelecer um espaço de diálogo entre a escola e as famílias, causando uma "escuta" atenta, bem como uma oportunidade de discutir a pluralidade das lógicas e culturas das famílias e aprofundar o conhecimento sobre suas relações no contexto educativo. A pesquisa apontou para a necessidade de compreender as estratégias de relacionamentos construídas pela escola, destacando como o confronto (THIN, 1998) entre as lógicas familiares e escolares possibilita a construção de estratégias de relacionamentos que qualifiquem a escola como lugar de acolhimento e educação das crianças.

PALAVRAS-CHAVE: Educação, Lógicas Familiares, Lógicas Escolares.

Abstract The paper presents part of the research called From family logic to school logic: paths and perspectives in children education. This study, as a qualitative approach of etnographic nature, started from the principle that a researcher must be inserted in the social field of the investigation. In this perspective, we tried to stablish the space for dialogue between schools and families, provoking an attentive "listening", as well as an opportunity to discuss the pluralism of logic and culture of families, and deepen the knowledge about its relations in the educational context. The research pointed out to the necessity of comprehend relationship strategies created by schools, detaching how the confrontation (THIN, 1998) between family and school logic enables the creation of relationship strategies that qualify a school as a place for childcare and education.

KEYWORDS: Education, Family Logic, School Logic. 


\section{Das lógicas familiares às lógicas escolares}

Este estudo iniciou a partir de resultados de uma pesquisa que apresentou a necessidade de ouvir o que as famílias dizem e pensam sobre a escola, congregando pesquisa e extensão no âmbito da universidade. Ele se apresenta como uma proposta de construção de experiências educativas para as crianças e suas famílias no contexto da escola. Assim, a primeira etapa da pesquisa desenvolveu-se por meio de um projeto de extensão denominado Tempo para as famílias, cujo público foram famílias das crianças da Educação Infantil e dos anos iniciais do Ensino Fundamental, de uma escola pública.

No decorrer do projeto, percebemos ${ }^{1}$ que as estratégias para o desenvolvimento da pesquisa foram direcionadas a algumas mulheres ${ }^{2}$, as quais se apresentaram como as responsáveis pela educação das crianças, demonstrando uma maior participação feminina na instituição. Nesse sentido, o estudo e planejamento das estratégias de pesquisa foram muito importantes, problematizando o papel do pesquisador nas dinâmicas propostas nos encontros.

A pesquisa acontecia em encontros quinzenais, nos quais eram discutidos assuntos relacionados à educação das crianças, aos temas referentes ao cotidiano dessas mulheres, às competências de educação designadas ao âmbito familiar e ao âmbito escolar. A intenção do estudo era compreender as lógicas familiares por meio das experiências do cotidiano, dos comportamentos, dos significados, dos valores e das culturas que envolvem as vivências pessoais em relação à educação das crianças e das famílias envolvidas. Destaca-se que o principal objetivo era confrontar essas lógicas com as adotadas no contexto escolar, oportunizando processos de interação entre as lógicas de educação existentes nesses contextos.

Nessa perspectiva, decidiu-se por um referencial teórico metodológico da pesquisa qualitativa de cunho etnográfico, uma vez que se considera ser o mais pertinente para a constituição do processo de pesquisa. André (2001) destaca alguns aspectos importantes que definem a pesquisa etnográfica, por exemplo, o papel da teoria na construção de categorias e a necessidade de respeitar princípios da etnografia, como a relativização (centrar-se na perspectiva do outro), o estranhamento ${ }^{3}$ (esforço deliberado do familiar como se fosse estranho) e o desenvolvimento do campo com uma observação planejada e instrumentos de registros muito bem elaborados. Bogdan e Bicklen (1997) também apresentam algumas características pertinentes à investigação qualitativa, que vão ao encontro deste projeto de pesquisa: a fonte direta de dados é o ambiente natural, cujo instrumento principal é o investigador; a investigação qualitativa é descritiva; o interesse está mais no processo do que nos resultados ou produtos; os investigadores tendem a analisar os seus dados de forma indutiva; o significado é de importância vital na abordagem qualitativa; compreendem-se os processo vividos nesta integração entre crianças, famílias e professores.

Assim, a abordagem da pesquisa foi qualitativa de cunho etnográfico, partindo do princípio de que a pesquisadora esteve inserida no campo social da investigação (contexto familiar e escolar), procurando compreender por meio da vivência no 
cotidiano os comportamentos, os significados, as lógicas, os valores e as culturas. Além disso, buscou-se estabelecer as relações necessárias com o contexto social, cultural e econômico em que as famílias estudadas se encontravam, chegando do particular ao geral. Segundo Fonseca (1999b, p. 59), o método etnográfico "é visto como o encontro tenso entre o individualismo metodológico (que tende à sacralização do indivíduo) e a perspectiva sociológica (que tende para a reificação do social)". Esta perspectiva permite que os problemas de pesquisa situem-se num contexto social e histórico, onde o pesquisador atuará como um artesão que irá construir um texto etnográfico a partir de suas reflexões teóricas.

Destaca-se que os estudos sobre as lógicas de educação das famílias e suas relações com o contexto escolar, como Thin $(1998,2006)$ e Vianna (2005), apontam para uma "confrontação" entre as lógicas do contexto familiar e do escolar. Nesta perspectiva, a pesquisa tomou por base teóricos como Fonseca (1999b) e Victora, Knauth e Hassem (2000), que possibilitaram conhecimentos e reflexões sobre a pesquisa qualitativa de cunho etnográfico. Além disso, estudos como Bilac (1995), Rosemberg (1995), Thin (2001 e 2006) e Sarti (1995) subsidiaram as análises e problematizações das relações entre os contextos familiares e escolares. Estes estudos foram fundamentais para uma interpretação do que as famílias dizem, do que dizem sobre o que fazem e do que elas realmente fazem em relação à educação dos filhos.

\section{Os caminhos e perspectivas da pesquisa}

Com o intuito de oportunizar um espaço de interação com as famílias, foi proposto um projeto de extensão denominado Tempo para as famílias. Nesses momentos, eram realizadas diversas dinâmicas, a fim de conhecer o público, ajudar no reconhecimento individual e coletivo, proporcionar momentos de diálogo e discutir diferentes temas, como identidades, famílias, educação dos filhos, dificuldades e questões relativas à escola.

Nesses encontros, o principal objetivo era escutar as famílias e, com isso, perceber e reconhecer a necessidade dessa tarefa. Foram realizados quinze encontros temáticos com as famílias ao longo do ano e, no final de cada encontro, era escrito um diário de campo, com anotações, observações, falas e comentários das mulheres nos encontros. É preciso salientar que fazer uma pesquisa de cunho etnográfico implica grande responsabilidade do pesquisador com suas anotações e memórias. Escrever o diário sempre foi um desafio, uma vez que não era possível realizar as anotações das falas das mulheres durante os encontros, para não causar constrangimentos. Assim, era necessário um esforço de memória para destacar expressões, detalhes, falas e diálogos.

O trecho abaixo expressa como o registro por meio do diário se tornava uma busca constante do pesquisador para que "não escapasse" a riqueza do cotidiano vivido:

Enquanto vão moldando a sua professora elas vão dizendo o que estão pensando, como é a sua professora. Di diz que as professoras deviam ter mais disponibilidade, ter mais tempo para poder avaliar cada aluno individualmente. 
Mi salienta que em sua época a sua professora era perfeita, pois a tratava como se ela, Mi, fizesse parte de sua família. Ressalta que as professoras devem ter atenção, responsabilidade. Ela diz que se as professoras tratassem seus alunos como a sua a tratava, eles iriam se interessar mais em aprender, iriam se desenvolver melhor, a educação seria melhor. Ter uma relação de amizade com os alunos. Ter carinho e afeto.

$\mathrm{B}$ (filho de $\mathrm{Mi}$ ) interfere na conversa diz que quando vocês se juntam com amor, não se largam mais. Mi diz que quando ela briga com o marido ou se separa, o menino presencia aquilo e já entende o que está acontecendo.

Mi salienta muitas vezes que a professora precisa ter uma relação de amizade e confianças com o aluno. (Diário de Campo - novembro de 2009).

Além dos diários de campo, foram realizadas ao final do ano entrevistas individuais com cinco mães participantes do projeto. Essas entrevistas foram feitas no âmbito familiar dessas mulheres, a partir de perguntas que direcionaram a conversa sobre a educação dos filhos e sua participação no projeto. A entrevista foi gravada em áudio, com a intenção de ter a precisão de detalhes, e também foram escritos diários sobre as impressões e observações feitas no decorrer da entrevista.

Considera-se que o primeiro ano de estudo e realização da pesquisa foi decisivo na construção de um espaço de interação com as famílias no contexto escolar, bem como no estabelecimento de diálogos específicos que ocorreram por meio das entrevistas realizadas no contexto familiar. Isso destacou a necessidade de ouvir o que as famílias dizem e pensam sobre a escola, o que foi oportunizado pelo projeto de extensão Tempo para as famílias, que foi o locus da pesquisa. Os encontros se mostraram como uma experiência rica, por meio dos quais pudemos conhecer a diversidade de interesses, de valores e de preocupações que as famílias possuem em relação à educação de seus filhos. Assim como a pesquisa realizada por Lahire (1997), consideramos que o "mito da omissão parental" se faz mais presente nos discursos ou em algumas experiências pontuais. O que se verificou no contexto pesquisado foi o desejo das famílias de diálogo e de participação efetiva, as preocupações pontuais acerca da educação escolar dos filhos, e, principalmente, um "olhar atento" em relação à vivência das crianças na escola. Essa pesquisa proporcionou às famílias momentos de "escuta sensível", nos quais as mulheres/mães ${ }^{4}$ dos alunos podiam, além de conversar sobre a educação de seus filhos, fazer observações a respeito da escola, de suas vidas e de suas dificuldades.

Destaca-se que a "escuta sensível" se apresenta como uma das dimensões da pesquisa. Nesses momentos, estamos atentos ao olhar, às falas, aos sentimentos do "outro", na tentativa de compreender a sua perspectiva, saindo de um lugar de alteridade para, a partir da reciprocidade, entender as lógicas construídas pelo outro. $\mathrm{O}$ outro, nesta pesquisa, foram as mulheres; quatro delas se destacaram pela assiduidade e pelo interesse na participação efetiva no projeto: DE, MIC, MI e FA ${ }^{5}$. Algumas falas destacam esta participação:

Ajudou, a gente saiu um pouco do estresse, pelo menos um dia da semana, de 15 em 15 dias tu sai um pouco da rotina e tu volta mais 
leve, com a cabeça menos atordoada, mais fácil de tu te comunicar com a família, não é só aquele robozinho, de manhã, levanta, lava roupa, faz comida... saiu um pouco, é uma coisa assim que tu relaxa, que até foi por isso que a MIC começou a ir comigo, porque ela foi a primeira vez ela foi e gostou, e aí a gente começou a ir mais, porque é uma coisa assim, que tu sai mesmo da tua rotina, sei lá, desvirtua. (Informação verbal) ${ }^{6}$

$\mathrm{Na}$ análise dos dados, foram construídas categorias recorrentes que se apresentam como indícios importantes. Uma delas refere-se à relação com a professora, que foi apontada como um fator importante na manutenção de um diálogo entre escola e família, na troca de informações sobre as experiências das crianças no contexto familiar. Salienta-se a dimensão do cuidado que a professora expressa ao olhar atentamente para a criança e para suas famílias. Foram vários os momentos em que as mulheres recorreram às suas experiências pessoais para expor o quanto essa relação é importante e definidora na educação das crianças, apontando que aspectos relativos às aprendizagens, como "gostar da matéria", estão vinculados à subjetividade de "saber entender a criança". Conforme anotamos no diário, "de dá uma importância muito grande à professora do seu filho, conta que ele ficou muito agressivo de uns tempos para cá. E a professora se mostrou muito interessada pela vida do seu filho". Comenta: "Ela me deu a maior força”.

Outros profissionais da escola, como membros da equipe de coordenação e direção, são apresentados na tentativa de construir essa relação entre escola e família, mas a presença da professora é destacada como o principal vínculo entre família, crianças e escola. A partir de nossas análises nos diários de campo, é possível concluir que a relação com a professora é reconhecida, pelas famílias pesquisadas, como um "elo" que se estabelece com a escola. Esse elo vai se consolidando a cada ano, de acordo com as experiências com as professoras e com a construção da historicidade da família na escola. Isso significa que não é apenas o tempo de frequência da criança na escola que interfere nas relações construídas com esta, mas também o tempo de frequência da família nesse ambiente, pois famílias com um maior número de filhos em diferentes idades na mesma escola ou em escolas diferentes tendem a conhecer a dinâmica dessas instituições, (re)conhecendo diferentes formas de se relacionar com as professoras e com a escola.

Esta questão vai ao encontro de outra categoria analisada, a socialização escolar, compreendida como a inserção das famílias e das crianças na compreensão e vivência das lógicas escolares, por exemplo, o cumprimento de rotinas, os horários, as regras na sua organização, a disciplina, as hierarquias, a participação em reuniões. Esta "socialização escolar" implica numa convivência mais tranquila de todos no contexto escolar, isto é, as famílias conhecem como funciona a escola e se engendram nessa lógica a tal ponto que ela influencia a socialização familiar e se aproxima dela.

Nas dinâmicas construídas para problematizar, junto com as famílias, suas lógicas de educação em seu contexto familiar, percebeu-se que, em alguns momentos, as famílias buscavam, por meio da socialização familiar, constituir lógicas semelhantes à da escola no que se referia à rotina durante o período letivo. A diferenciação entre 
os momentos de trabalho (tarefa, estudo) e os de lazer (jogos, brincadeira, televisão) são bons exemplos de como a organização da casa se dava em função da escola. Outro elemento evidenciado nesta perspectiva foi a busca do cumprimento de regras e estratégias de punição que se estendiam da escola para casa, isto é, quando acontecia algum evento na escola, a punição ocorria na rotina da criança em casa.

A pesquisa realizada por Vianna (2005), sobre a longevidade escolar em famílias populares, apresenta que "processos de socialização familiar, produtores de traços disposicionais, são potencialmente desencadeadores de elementos favorecedores - ou dificultadores - de êxito escolar, conforme as afinidades ou os distanciamentos com relação à escola que esses traços engendram" (p. 14).

No âmbito deste estudo, foi possível compreender que as famílias apresentavam, através da socialização familiar, ações que se aproximavam da socialização escolar, ou seja, as famílias pesquisadas buscavam formas de estruturar suas lógicas de ação para estabelecer uma relação de reciprocidade com a escola. Nesta perspectiva, como aponta Vianna (2005), esses processos são construídos no âmbito familiar para criar afinidades com a escola, incentivando a criança a incorporar a cultura da escola e reconhecendo, como Singly (2007), que o processo de escolarização para as famílias é fundamental para melhorar a posição no espaço social.

Outra questão que se destacou na pesquisa foi o conceito de família expresso pela escola, que muitas vezes é consequência da abordagem dos cursos de formação de professores, os quais não contemplam estudos da sociologia e antropologia da família. Os professores, em seus cursos de licenciatura, acabam por conhecer a criança enquanto aluno e/ou sujeito epistêmico, e não na sua complexidade enquanto sujeito histórico e social. Essa afirmação foi explicitada em diversos momentos da pesquisa, pelas conversas com diferentes sujeitos da escola, que denominavam as famílias das crianças com adjetivos como famílias desestruturadas, carentes, problemáticas (informação verbal).

Conclui-se que, muitas vezes, as famílias das crianças não são compreendidas na complexidade das relações sociais, culturais, econômicas e de afeto que as constituem. As crianças frequentemente ficam com aquele que pode "cuidar melhor", como uma "estratégia de sobrevivência" (Fonseca, 1993). Portanto, as crianças nem sempre vivem e moram com seus pais, mas com outras pessoas, parentes ou não, que compõem o seu "contexto familiar".

As trajetórias e disposições construídas pelas famílias, em especial pelas mulheres, oportunizam que elas considerem a educação das crianças como algo prioritário e que merece um investimento por parte de suas famílias. Nesse sentido, este estudo aponta que as famílias, já desde que os filhos frequentavam a Educação Infantil, constituíram em suas lógicas elementos favorecedores para a construção de uma relação de reciprocidade com a escola. Destacamos que essa reciprocidade causa conflitos, pois quanto mais as famílias estão implicadas no contexto da escola, maiores são suas necessidades e suas críticas, pois também desejam que a "escola cuide como a gente cuida" (informação verbal). 
Nesse sentido, muitas vezes elas reivindicam reconhecimento e participação no contexto da escola, por exemplo, na organização do calendário escolar, no conselho da merenda escolar e no próprio cotidiano da escola. Desejam que a escola tenha atitudes de "cuidado" com as crianças. isso:

Conforme é expresso nos diários de campo, as falas das mães demonstram

Tem professora que larga no pátio e não cuida.

Tem que chamar algumas mães para ajudar a cuidar no recreio das crianças, precisa ter um adulto junto, tem umas pessoas que ficam cuidando, mas são adolescentes, só querem saber de namorar e não cuidam as crianças. Imagina os da quinta, cuidando o pré.

As crianças precisam fazer algo junto, um recreio mais orientado, no meu tempo era assim, tempo para jogar bola, vôlei, ler livro, pular corda.

Meu filho corre para trocar o livro antes de sair porque na hora do recreio a biblioteca fica fechada.

Eu trago meu filho todos os dias, sempre fico preocupada e depois que saio daqui fico com o celular sempre na mão. Eu tenho muito medo do recreio. (Diário de campo - outubro de 2009)

$\mathrm{E}$ as férias? Por que não consultam a comunidade? E os horários de reunião dos profes!? Tão sempre em reunião e nem perguntam qual o melhor horário pra gente! (Diário de campo - agosto de 2009)

Este estudo apontou que a "confrontação desigual", analisada na tese de Thin (1998), é amenizada em termos de prática quando as famílias consideram a educação como um investimento. Isso significa que as variações das lógicas familiares não entram em contradição com as lógicas escolares quando as famílias potencializam elementos que desencadeiam e favorecem afinidades com as lógicas da escola. Mas é importante salientar que essa "relação de reciprocidade", encontrada no grupo pesquisado, não equivale ao desempenho das crianças no contexto das aprendizagens escolares, mas na dinâmica das relações construídas entre família e escola.

A pesquisa realizada tem apontado para uma perspectiva ampliada do processo de confrontação discutido por Thin (2006), já que as famílias estudadas apresentam, em sua organização, uma lógica construída e articulada com a lógica da escola no que se refere aos horários e rotinas.

Nesta perspectiva, MIC apresenta suas ideias sobre a organização do cotidiano da sua casa e da escola:

[...] aqui eles já conhecem, aqui a gente tem hora pra deitar e pra levantar, a minha pequena que se levanta mais cedo, mas os outros já acostumaram com o horário deles, eles sabem que $9 \mathrm{~h}$ a gente janta, aí eles escovam os dentes, cama, e aí às $7 \mathrm{~h}$, $6 \mathrm{~h}$ e meia, todo mundo se levanta, já têm os horários deles, ele sabem que tem horário pra brincar, tem os horários pra estuda, tem tudo direitinho, pelo costume mesmo, acostumo eles assim, o meu guri que dorme mais por causa dos remédios, né? (Informação verbal) 
MIC, ao analisar a escola, diz:

[...] eu acho que a forma deles é parecida com a da gente, né, no caso porque pra tudo tem que ter um horário, é o que a gente procura botar pra eles [...] é a questão de ter as regras deles, no caso, tem horário pra sair, tem horário pra merenda, eu acho que pra mim é muito parecido. (Informação verbal)

É importante salientar que resultados de algumas pesquisas recentes no Brasil e no exterior (CAMPOS, 1997, 2004) indicam que a relação da escola com a família, além do currículo e da formação de professores, são fatores indicativos para a qualidade da educação das crianças pequenas. Neste contexto, é preciso compreender os significados dos processos vividos na relação entre as crianças, suas famílias e a escola, na tentativa de problematizar as lógicas construídas e/ou confrontadas entre os contextos familiares e escolares.

\section{Participação das famílias: desafios à prática educativa}

Este estudo apresentou, por meio do projeto Tempo para as famílias, uma possibilidade de, no cotidiano da escola, construir um espaço para conhecer de forma mais singular e pontual as pluralidades das lógicas e culturas das famílias. Este projeto destacou-se como um espaço coletivo e democrático reconhecido no contexto escolar, que oportunizou às famílias o diálogo, a escuta e a comunicação, tão raros nas relações estabelecidas no cotidiano da escola, como destaca uma das participantes em relação a sua experiência no projeto:

Foi muito bom, tá sendo muito bom, espero que vocês voltem rápido, porque eu gostei, assim a gente se comunica mais, conversa mais, como tu dissestes, tem certas que a coisas que a gente prefere nem falar na frente de todo mundo, mas comigo graças a Deus o que tu me perguntar eu vou te responder, porque eu não tenho nada a esconder, pra mim a minha vida por enquanto tá boa, meus filhos são bem tratado no colégio, é um colégio que educa bem, é um colégio que tem várias propriedades, assim vamos supor, propriedades não é variedades, eles brincam, tem psicólogo, tem assistente social, pra mim aquele colégio é uma maravilha. (Informação verbal)

A pesquisa apontou que a participação das famílias como uma política educativa da escola precisa ser considerada em toda a complexidade, demarcando estratégias profícuas, como a utilização de horários adequados à realidade das famílias, dinâmicas convidativas e linguagem compreensível. Além disso, este deve ser um processo cotidiano, e não uma política de eventos, sejam eles para comemorações ou reclamações. Nesta perspectiva, acolher as famílias no cotidiano da escola implica numa decisão política e pedagógica que prevê ações e interações vivenciadas no cotidiano, que podem ser pensadas a partir das seguintes questões: qual o local onde as famílias são recebidas na escola? As portas e portões estão sempre abertos? Em quais horários e como são recebidas as famílias no cotidiano da escola? Como são acolhidas suas críticas e sugestões? Quais os mecanismos de participação na gestão da escola em que as famílias são incluídas? Quais os tempos e espaços que as professoras encontram no cotidiano para estabelecer um diálogo efetivo com as famílias das crianças? 
É possível afirmar que as questões acima podem se tornar definidoras de estratégias para a construção de relacionamentos entre o contexto escolar e o familiar, com o objetivo de considerar a participação das famílias como uma política educativa. Para isso, é necessária a construção de propostas emergentes no cotidiano educativo que visem a desconstrução de um modelo idealizado de família, além de um projeto educativo que consolide estratégias de relacionamentos diários e cotidianos, indo além de eventos, reuniões e bilhetes. Dessa forma, é preciso considerar a participação das famílias como eixo de um processo desenvolvido no trabalho educativo com as crianças e na gestão da escola, principalmente encontrando nas famílias importantes interlocutores e protagonistas na construção de um projeto educativo compartilhado.

\section{Referências}

ANDRÉ, M. Pesquisa em educação: buscando rigor e qualidade. Cadernos de Pesquisa, São Paulo, n. 113, p. 51-64, 2001.

BILAC, E. D. Sobre as transformações nas estruturas familiares no Brasil: notas muito preliminares. In: RIBEIRO, I.; RIBEIRO, A. C. (Orgs.). Família em processo contemporânea: inovações culturais na sociedade brasileira. São Paulo: Loyola, 1995, p. 43-61.

BOGDAN, R. C.; BIKLEN, S. K. Investigação qualitativa em educação: uma introdução à teoria dos métodos. 2.ed. Porto: Porto, 1997.

BRASIL. Ministério da Educação. Secretaria de Educação Básica. Parâmetros Nacionais de qualidade para a Educação Infantil. Brasília: MEC, 2004.

CAMPOS, M. M. Educação Infantil: o debate e a pesquisa. Cadernos de pesquisa, São Paulo, n. 101, p. 113-127, 1997. 127,1999

A mulher, a criança e seus direitos. Cadernos de pesquisa, São Paulo, n. 106, p. 117-

CAMPOS, M. M.; FÜLLGRAF, J.; WIGGERS, V. Qualidade na Educação Infantil: alguns resultados de pesquisas. Brasília: UNESCO, 2004. (Texto elaborado para o projeto revisão de políticas e serviços de educação infantil no Brasil, mimeo.)

FONSECA, C. Criança, família e desigualdade social no Brasil. In: RIZZINI, I. (Org.). A criança no Brasil hoje: desafio para o terceiro milênio. Rio de Janeiro: Ed. Universitária Santa Ursula, 1993.

FONSECA, C. O abandono da razão: a descolonização dos discursos sobre a infância e a família. In: SOUSA, Edson (Org.). Psicanálise e colonização: leituras do sintoma social no Brasil. Porto Alegre: Artes e Ofícios, 1999a.

FONSECA, C. Quando cada caso NÃO é um caso: Pesquisa etnográfica e educação. Revista Brasileira de Educação, São Paulo, n. 10, p. 58-78, jan./abr. 1999 b.

LAHIRE, B. Sucesso escolar nos meios populares: as razões do improvável. Tradução por Ramon Américo Vasques e Sonia Goldefer. São Paulo: Ática, 1997.

ROSEMBERG, F. A criação de filhos pequenos: tendências e ambigüidades contemporâneas. In: RIBEIRO, I.; RIBEIRO, A. C. T. (Orgs.). Família em processos contemporâneos: Inovações culturais na sociedade brasileira. São Paulo: Loyola, 1995, p. 167-190.

ROSEMBERG, F. O estado dos dados para avaliar políticas de educação infantil. Estudos em avaliação educacional, São Paulo, n. 20, p. 5-57, jul./dez. 1999. 
ROSEMBERG, F. Avaliação de programas, indicadores e projetos em educação infantil. Revista Brasileira de Educação, São Paulo, n. 16, p. 19-26, jan./abr. 2001.

Políticas educacionais e de gênero. Porto Alegre: SMED, março, 2003. Palestra de abertura do ano letivo da Secretaria Municipal de Educação de Porto Alegre.

SARTI, C. A. O valor da família para os pobres. In: RIBEIRO, I.; RIBEIRO, A. C. T. (Orgs.). Família em processos contemporâneos: Inovações culturais na sociedade brasileira. São Paulo: Loyola, 1995, p. 131-150.

SINGLY, F. de. Sociologia da família contemporânea. Tradução por Clarice Ehlers Peixoto. Rio de Janeiro: FGV, 2007.

THIN, D. Quartiers populaires - Lécole et les familles. (Bairros Populares: a escola e as famílias.) Lyon: Universidade de Lyon II, 1998. Tese de Doutorado. Tradução por Ramon Correa de Abreu, FaE/UFMG. (Digitado)

. Famílias de camadas populares e a escola: confrontação desigual e modos de socialização. Tradução por Janine Françoise Andrée Houard e Revisão Técnica por Lea Pinheiro Paixão (Digitado), 2005.

. Para uma análise das relações entre famílias populares e escola: confrontação entre lógicas socializadoras. Revista Brasileira de Educação, Rio de Janeiro, v. 11, n. 32, p. 211-225, maio/ago. 2006

VIANNA. M. J. B. As práticas socializadoras familiares como locus de constituição de disposições facilitadoras de longevidade escolar em meios populares. Educação e Sociedade, Campinas, v. 26, n. 90, jan./abr. 2005.

VICTORA, C. G.; KNAUTH, D. R.; HASSEN, M. de N. A. Pesquisa qualitativa em saúde: uma introdução ao tema. Porto Alegre: Tomo, 2000.

Notas

${ }^{1}$ Esta pesquisa contou com a participação de duas bolsistas de Iniciação Científica

${ }^{2} \mathrm{Na}$ elaboração do projeto, o grupo tinha como hipótese que pais (homens) apresentariam-se como responsáveis pela educação das crianças pequenas, participando dos encontros que eram abertos, mas foi possível constatar no decorrer do projeto que foram as mulheres as principais participantes. Este fato também foi evidenciado no decorrer da pesquisa, já que a maioria dos responsáveis pelas crianças que circulam pela escola, são mulheres.

${ }^{3}$ Fonseca (1999) considera estranhamento o que é especificamente desconhecido em algum acontecimento no campo.

${ }^{4} \mathrm{O}$ grupo foi composto por 15 mulheres, todas mães das crianças estudantes da escola, que participaram de forma esporádica dos encontros, sendo que cinco tiveram uma participação mais efetiva e foram estas que realizamos entrevistas.

${ }^{5}$ Decidimos não usar o nome dos participantes, mas letras que indicassem os sujeitos pesquisados.

* Professora Doutora da Universidade Federal do Rio Grande do Sul, Porto Alegre, Rio Grande do Sul, Brasil. 
A participação das famílias como uma política educativa

\section{Correspondência}

Simone Santos de Albuquerque - Universidade Federal do Rio Grande do Sul, Faculdade de Educação. Av. Paulo Gama, s/n, prédio, 12201, Centro, CEP: 90046-900 - Porto Alegre, Rio Grande do Sul, Brasil. E-mail: sialbuq@gmail.com

Recebido em 30 de junho de 2013

Aprovado em 10 de julho de 2014 